\title{
PENGARUH KEMATANGAN, KINERJA DAN PEMANFAATAN TEKNOLOGI INFORMASI TERHADAP IMPLEMENTASI SI DI SMK NEGERI JAKARTA TIMUR DENGAN MODEL COBIT FRAMEWORK
}

\author{
Wowon Priatna \\ Program Studi Magister Teknik Informatika, Binus University \\ Jl. Kebon Jeruk Raya No. 27. Kebon Jeruk Jakarta Barat 11530 \\ Email: wo2n_engineer@yahoo.com.sg
}

\begin{abstract}
Abstrak
Penelitian ini bertujuan untuk memperoleh pemahaman tentang tingkat kematangan ada atau tidaknya pengaruh teknologi informasi, kinerja dan pemanfaatan Teknologi Informasi Implementasi Sistem Informasi di Sekolah Menengah Kejuruan Negeri di Jakarta Timur pada manajemen dan penggunaan Teknologi Informasi. Kuesioner dibagikan kepada para guru dan karyawan responden berdasarkan indikator diambil dari variabel kematangan teknologi informasi, kinerja dan pemanfaatan teknologi informasi dengan Domain COBIT 4. Metode dalam penelitian ini adalah teknik pengumpulan data, metode analisis data, metode analisis faktor. Pengolahan data menggunakan SPSS untuk menguji reliabilitas, uji validasi dan analisis faktor untuk mengurangi variabel yang ada yang pada akhirnya akan menghasilkan faktor baru. Hasil penelitian menunjukkan bahwa 5 faktor baru yaitu ketersediaan tata kelola TI, ketersediaan pengelolaan keamanan, peningkatan kualitas sistem, peningkatan kualitas sistem informasi, pengelolaan kesiapan kinerja TI. Kesimpulan dari penelitian ini adalah terciptanya model dari 5 faktor yang memiliki pengaruh signifikan terhadap pelaksanaan Sistem Informasi.
\end{abstract}

Kata kunci: Maturity, Pemanfaatan TI, Kinerja TI, COBIT, Analisis Faktor, Implementasi Sistem Informasi

\begin{abstract}
This study aims to gain an understanding of the level of maturity of the presence or absence of the influence of information technology, performance and utilization of Information Technology on Information System Implementation at State Vocational Middle School in East Jakarta on the management and use of Information Technology. Questionnaires were distributed to the teachers and employees of the respondent based on indicators drawn from variable maturity of information technology, performance and utilization of information technology by Domain COBIT 4. Methods used in this research are the data collection techniques, methods of data analysis, factor analysis method. Processing data using SPSS to test reliability, test validation and factor analysis to reduce the variables that exist that will eventually produce a new factor. The results showed that 5 new factors that is Availability Manage IT, Availability Manage security, improvement quality System, quality information System, manage performance readiness. The conclusion of this research is the creation of the model of 5 factors that have significant influence on the implementation of the Information System.
\end{abstract}

Keyword: Maturity, IT Utilization, IT Performance, COBIT, Factor Analysis, Implementation Information System

\section{Pendahuluan}

Seiring dengan kemajuan teknologi yang telah terpengaruh dalam segala aspek kehidupan baik di bidang ekonomi, politik, kebudayaan, seni dan bahkan di dunia pendidikan. Kemajuan teknologi adalah sesuatu yang tidak bisa kita hindari dalam kehidupan ini, karena kemajuan teknologi akan berjalan sesuai dengan kemajuan ilmu pengetahuan. Setiap inovasi diciptakan untuk 
memberikan manfaat positif bagi kehidupan manusia. Memberikan banyak kemudahan, serta sebagai cara baru dalam melakukan aktivitas manusia.

Di instusi pendidikan TI sudah menjadi sumber dari ilmu pengetahuan. Kenyataan dipicu dari dihubungkannya sebagai sumber dan pakar ilmu pengetahuaan melalui sebuah jejaring informasi yang di fasilitasi oleh internet. TI di lembaga pendidikan berfungsi sebagai alat bantu atau sarana penyelenggaraan kegiatan belajar mengajar maupun aktivitas pembelajaran. Hal ini terkait dengan semakin banyaknya guru dan dosen menggunakan berbagai peralatan TI untuk membantu mereka memberikan penjelasan materi ajar yang ada dalam berbagai ilustrasi visual atau multimedia yang menarik [1].

Untuk mengetahui pengaruh TI terhadap kinerja sistem informasi dalam mendukung penyelenggaraan pendidikan perlu diadakan pengukuran kematangan teknologi informasi dengan menggunakan model COBIT. Manajemen sekolah diharapkan dapat mengukur keberhasilan penerapan TI dalam mendukung kinerja Sistem Informasi dengan proses-proses pengendalian berdasarkan yang terdapat dalam keempat Domain COBIT.

Penelitian ini akan mencari faktor-faktor yang mempengaruhi implementasi SI melalui proses pengendalian TI berdasarkan COBIT Framework, sehingga akan didapatkan faktor baru yang akan diprediksi seberapa besar pengaruhnya menggunakan metode regresi linier dan analisis jaringan syaraf Tiruan.

\section{Landasan Teori}

\subsection{Kematangan Teknologi Informasi}

Konsep kematangan teknologi informasi digunakan untuk menentukan sejauh mana manajer menggunakan sistem informasi berbasis komputer [2]. Sedangkan menurut [3] Kematangan Teknologi informasi adanya formalisasi dalam perencanaan, pengendalian, pengorganisasian, dan pengintegrasian aktivitasaktivitas yang berhubungan dengan teknologi informasi. Dengan tingkat kematangan teknologi informasi manajemen dapat mengukur posisi proses sistem informasi dengan menilai hal yang diperlukan untuk dapat meningkatkannya.

\subsection{Kinerja Teknologi Informasi}

Penilaian kinerja adalah penentuan secara periodik efektifitas operasional organisasi, bagian organisasi dan karyawannya berdasarkan sistem standar yang telah ditetapkan [4]. Untuk mengurangi resiko kegagalan teknologi informasi, organisasi harus mampu memprediksi hasil dari teknologi informasi yang sudah dijalankan, agar tahap pengembangan teknologi informasi berlangsung dengan baik.

\subsection{Pemanfaatan TI}

Pemanfaatan teknologi informasi merupakan manfaat diharapkan oleh pengguna TI dalam melaksanakan tugas yang tolok ukurnya berdasarkan frekuensi penggunaan dan diversitas aplikasi yang dilakukan [5]. Pemakaian tersebut bisa berupa shared database, spreadsheet, electronic data processing (EDP), electronic fund transfer (EFT), penggunaan internet dan intranet. Sistem yang diperoleh dari pemanfaatan Teknologi Informasi mempunyai ketelitian (accuracy) dan ketepat waktuan (timeliness) sehingga dapat meningkatkan efisiensi dan efektivitas dalam pelaksanaan pekerjaan apabila dibandingkan dengan cara manual atau konvensional, sehingga Teknologi informasi dapat dirasakan manfaatnya dalam menunjang kegiatan.

\section{$2.4 \quad$ COBIT Framework}

COBIT (control objectives for Information and Related Technology) adalah sebuah framework yang membantu manajer menjembati gap antara tujuan untuk keperluan pengendalian, permasalahan teknik dan resiko bisnis serta mengkomunikasikan level pengendalian stakeholder [6]. Prinsip dasar dari framework COBIT yaitu menyediakan informasi yang diperlukan untuk mencapai tujuan perusahaan. Perusahaan perlu untuk mengatur dan mengontrol IT Resource dengan menggunakan sekumpulan proses yang terstruktur untuk mengirimkan service informasi yang diperlukan.

Framework COBIT secara keseluruhan terdiri dari 4 domain dengan terdapat 34 macam proses seperti terlihat pada gambar 1 .

COBIT mendefiniskan aktivitas-aktivitas TI dalam proses umum, melalui 4 (empat) domain yang akan memetakan area tanggung jawab tradisional TI. Area tanggung jawab tersebut di mulai dari merencanakan, menyusun, menjalankan dan memonitornya.

1. Planning and Organise

Domain ini menyangkut strategi dan taktik, serta difokuskan pada penentuan arah TI yang dapat memberikan kontribusi terbaik dalam pencapaian tujuan-tujuan dan sasaran bisnis. Lebih lanjut dari strategi yang merupakan penjabaran dari visi dan misi perusahaan perlu untuk direncanakan, dikomunikasikan dan diatur dengan perfektif yang berbeda. Dengan demikian diperlukan keterlibatan dari perusahaan secara keseluruhan dan juga teknologi infrastrukur. 


\section{Aquire and Implement}

Untuk merealisasikan strategi TI, solusi TI perlu didefinisikan, dikembangkan atau dipelajari sebagaimana diimplementasikan dan diintegrasikan kedalam proses bisnis. Sementara itu, perubahan dan perawatan sistem yang ada tercakup dalam domain AI untuk memastikan penyelesaian yang berkelanjutan memenuhi tujuan dan sasaran bisnis.

\section{Deliver and Support $(D S)$}

Domain ini difokuskan pada actual delivery dari layanan yang dibutuhkan, yang mana melibatkan layanan pengiriman, manajemen keamanan dan kelancaran, pendukung layanan bagi user dan manajemen data serta fasilitas operasional.

\section{4. $\quad$ Monitor and Evaluate (ME)}

Semua proses TI perlu dinilai secara berkala untuk mengetahui kualitas dan pelaksanaan terhadap pemenuhan kebutuhan pengendalian. Domain ini di focuskan untuk mengetahui performance manajemen, memonitor pengendalian internal, pelaksanaan peraturan dan penyediaan pengelolaan.

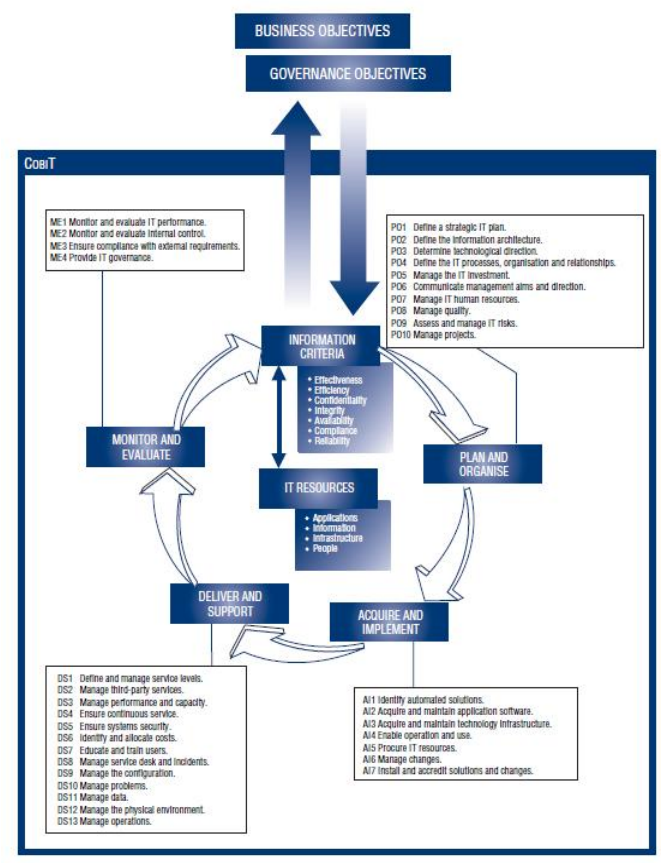

Gambar 1. Framework COBIT 4.1 [7]

\subsection{Analisis Faktor}

Analisis faktor adalah nama yang diberikan kepada sekelompok teknik statistik yang dapat digunakan untuk menganalisis keterkaitan antara sejumlah besar variabel dan menjelaskan variabel dalam segi dimensi.

Analisis faktor merupakan salah satu metode multivariate yang digunakan untuk menganalisis variabel-variabel yang diduga memiliki keterkaitan satu sama lain sehingga keterkaitan tersebut dapat dijelaskan dapat dikelompokkan menjadi faktor yang tepat.

Analisis faktor menganalisis dari sejumlah variabel bebas dari suatu pengukuran dan pengamatan yang dititikberatkan pada kenyataan yang sebenarnya serta menganalisis hubungan antara variabel untuk menetapkan apakah variasivariasi yang nampak pada variabel tersebut berdasarkan sejumlah faktor dasar variabel yang ada.

\subsection{Regresi}

Analisis regresi adalah sebuah teknik statistika untuk membentuk suatu model dalam menentukan hubungan kausal antara dua peubah atau lebih [8]. Model ini merupakan fungsi dari peubah-peubah tersebut dan digunakan untuk memahami, menerangkan dan memprediksikan perilaku sistem yang diamati.

\subsection{Jaringan Syaraf Tiruan}

Jaringan syaraf tiruan merupakan suatu metode pengelompokan dan pemisahan data yang prinsip kerjanya sama seperti jaringan syaraf pada manusia. Arsitektur jaringan syaraf tiruan merupakan suatu susunan yang terdiri dari input dan output. Akan tetapi setelah mengalami perkembangan, maka arsitektur jaringan syaraf tiruan terdiri dari input, hidden layer, dan output, dimana pada setiap input, dan hidden layer terdapat neuron-neuron yang berbeda antara satu sama lain.

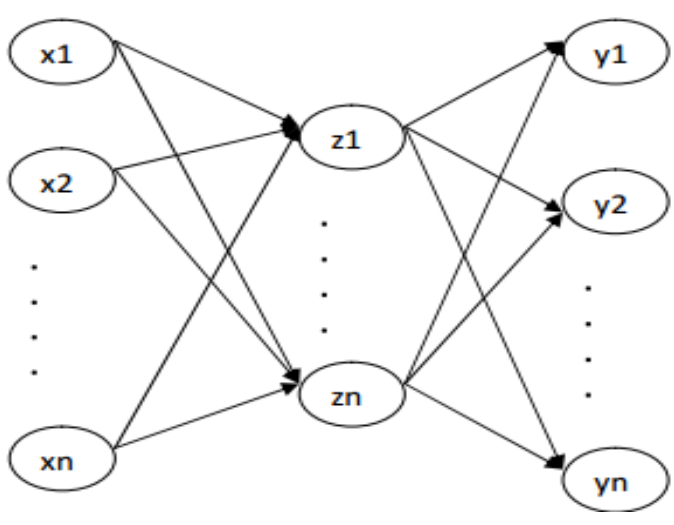

Gambar 2. Arsitektur jaringan syaraf tiruan

\section{Metodologi Penelitian}

Penelitian ini besifat kuantitatif untuk mendapakan gambaran yang jelas mengenai implementasi Teknologi informasi berdasarkan prosedur standar COBIT yang dikeluarkan oleh ISACA. Data yang digunakan dalam penelitian ini adalah data premier yang diperoleh dengan 
122 Journal of Information Systems, Volume 8, Issue 2, October 2012

TABEL I

HASIL ANALISIS FAKTOR

\begin{tabular}{|c|c|c|c|c|}
\hline Faktor & Variabel & Bobot & Indikator yang membentuk faktor & Nama Faktor \\
\hline \multirow[t]{6}{*}{1} & AI4 & 0.776 & Manage Changes & Availability Manage IT \\
\hline & PO4 & 0.738 & Define IT Proses, Organitation and Relationship & \\
\hline & PO8 & 0.693 & Manage quality & \\
\hline & PO7 & 0.663 & Manage IT Human Resources & \\
\hline & $\mathrm{PO} 3$ & 0.657 & Determine Technological Direction & \\
\hline & PO10 & 0.652 & Manage Project & \\
\hline \multirow[t]{8}{*}{2} & DS10 & 0.693 & Manage data & Availability Manage security \\
\hline & DS11 & 0.671 & Manage the physical environment & \\
\hline & DS6 & 0.629 & Educate and train users & \\
\hline & DS2 & 0.627 & Manage performance and capacity & \\
\hline & PO1 & 0.552 & Define IT Plan & \\
\hline & DS3 & 0.534 & Ensure continuous service & \\
\hline & DS1 & 0.526 & Define and manage service levels & \\
\hline & DS4 & 0.524 & Ensure systems security & \\
\hline \multirow[t]{4}{*}{3} & DS8 & 0.644 & Manage the configuration & Improve quality System \\
\hline & ME2 & 0.622 & Provide IT Governance & \\
\hline & DS7 & 0.586 & Manage service desk and incident & \\
\hline & AI7 & 0.552 & install and accredit solutions and changes & \\
\hline \multirow[t]{4}{*}{4} & $A I 3$ & $\begin{array}{l}0.745 \\
0.615\end{array}$ & $\begin{array}{l}\text { Enable Operation and Use } \\
\text { Comunitate Management Aims And Direction }\end{array}$ & quality information System. \\
\hline & PO6 & & & \\
\hline & & & acquire and maintain application software & \\
\hline & $A I 2$ & 0.533 & & \\
\hline \multirow[t]{6}{*}{5} & & & Define The Information Architecture & manage performance readiness. \\
\hline & $\mathrm{PO} 2$ & 0.721 & & \\
\hline & & & Monitoring and evaluate IT Performance & \\
\hline & ME1 & 0.690 & & \\
\hline & & & Manage IT Investment & \\
\hline & PO5 & 0.611 & & \\
\hline
\end{tabular}

metode angket tentang kematangan, kinerja, dan pemanfaatan Teknologi serta implementasi Sistem informasi yang diperolehdari SMK Negeri yang berada di Jakarta Timur. Adapun jumlah sampel sebanyak 3 (tiga) SMK Negeri.

\section{Hasil dan Pembahasan}

\subsection{Gambaran Responden}

Berdasarkan hasil penyebaran kuesioner yang telah dikumpulkan, hanya mendapat 105 
kuesioner yang dapat diolah. Kepala sekolah 3 $(0.2 \%)$, Wakasek $15(14.2 \%)$, guru 51(48.5\%), tata usaha 30(28.5\%) dan Staff TI $6(0.57 \%)$.

\subsection{Hasil Uji Model penelitian}

Hasil output SPPS menunjukan Cronbach's Alpha dari ke 31 variabel adalah sebesar 0.914 sehingga instrumen yang digunakan dalam penelitian ini sudah dianggap reliabel untuk pernyataan dalam masing-masing variabel yang digunakan dalam penelitian ini. Dan hasil validasi menggunakan SPSS, dari 105 kuesioner yang diolah semuanya valid dan siap untuk digunakan untuk data penelitian.

\subsection{Hasil Analisis Faktor}

Dengan memanfaatkan hubungan korelasi antara variabel akan digunakan variabel baru yang jumlahnya lebih sedikit dari pada jumlah awal. Dari hasil analisis faktor di dapatkan 5 faktor baru yang mempengaruhi implementasi sistem informasi. Hasil lengkap dari analisis faktor selengkapnya pada tabel I

Hasil analisis faktor menunjukkan terdapat 5 faktor yang mempengaruhi implementasi sistem informasi yang menjelaskan variansi total $90.07 \%$ dengan perinciannya adalah faktor Availability Manage IT 17.47\%, faktor Availability Manage security $31.17 \%$, faktor Improve quality System $15.75 \%$, faktor quality information System sebesar $12.41 \%$ dan faktor manage performance readiness sebesar $13.26 \%$.

\subsection{Hasil Multiple Regression}

Dengan menggunakan penilaian Implementasi SI sebagai dependent variable dan factor score sebagai independent variable, maka analisis dilanjutkan dengan analisis regresi. Dari hasil analisis regresi faktor yang dilakukan maka ditemukan persamaan yang dapat digunakan sebagai formula untuk menggambarkan pengaruh faktor terhadap implementasi SI pada seluruh SMK Negeri Jakarta Timur. Dengan menggunakan rumus pada Multiple Regression peneliti mendapatkan hasil sebagai berikut:

$$
Y=a+b_{1} X_{1}+b_{2} X_{2}+b_{3} X_{3}+b_{4} X_{4}+b_{5} X_{5}
$$

\footnotetext{
Keterangan:

$\mathrm{Y}=$ Model Implementasi SI

$\mathrm{a}=$ Nilai Constant

$\mathrm{X}_{1}=$ Availability Manage $\mathrm{IT}$

$\mathrm{X}_{2}=$ Availability Manage security

$\mathrm{X}_{3}=$ improvement quality System

$\mathrm{X}_{4}=$ quality information System

$\mathrm{X}_{5}=$ manage performance readiness
}

Maka didapatkan model persamaan persamaan regresi dibawah ini:

$Y=7.848+0.193 X_{1}+0.242 X_{2}+0.047 X_{3}$ $+0.795 X_{4+} 0.387 X_{5}$

Hasil pengujian persamaan regresi dengan menggunakan koefesien determinasi dengan pengolahan software SPSS menghasilkan:

TABEL II

\begin{tabular}{ll} 
KESIMPULAN KOEFESIEN DETERMINASI \\
\hline Koefesien korelasi $(\mathrm{R})$ & 0.898 \\
\hline Keeratan Hubungan & Sangat Kuat \\
Koefesien Determinasi & 0.807 \\
Tingkat Pengaruh & $80.7 \%$ \\
Pengaruh lain & $19.3 \%$ \\
Adjusted R & 0.797 \\
\hline
\end{tabular}

Dari tabel II faktor yang mempengaruhi system informasi sebesar $80.7 \%$ sedangkan $19.3 \%$ dipengaruhi oleh faktor lain.

\subsection{Hasil Uji Jaringan syaraf Tiruan}

Pembentukan model prediksi untuk menentukan parameter dari arsitektur jaringan yang akan digunakan dalam pembelajaran. Pembentukan model prediksi menggunakan jaringan Propagasi Balik (Backpropagation) dengan melakukan uji pemasukan hidden layer beberapa kali. Jumlah variabel input adalah 5 variabel dari hasil analisis faktor yang telah terbentuk. Sebelum digunakan untuk proses pelatihan, harus dilakukan scaling terhadap nilai input dan target. Data dilakukan normalisasi untuk mendapatkan nilai 0 dan 1 . Kriteria yang digunakan untuk pelatihan pada penelitian ini

TABEL III KRITERIA PARAMETER PELATIHAN

\begin{tabular}{ll}
\hline Karakteristik & Spesifikasi \\
\hline Arsitektur Jaringan & Multilayer Fungsi \\
Algoritma Pembelajaran & Propagasi Balik \\
Jumlah Node Input & 5 \\
Jumlah Node Tersembunyi & $1,5,10$ \\
Fungsi Aktivasi jaringan tersembunyi & Purelin \\
Jumlah node lapisan output & 1 \\
Fungsi Aktivasi & Traingdx \\
\hline
\end{tabular}

Peramalan menggunakan metode jaringan syaraf tiruan dengan bantuan software Matlab memerlukan beberapa input data, baik data internal maupun data eksternal. Data internal adalah sebagai berikut:

a. Epoch

Satu epoch atau satu iterasi adalah siklus yang melibatkan seluruh pola data training. Dalam proses pembelajaran Backpropagation biasanya memerlukan banyak epoch. Epoch yang digunakan dalam penelitian ini adalah default dari software 
Matlab sebesar 1000 epoch. Jumlah tersebut diperkirakan cukup dan dapat mendapatkan jaringan yang optimal.

b. Hidden layer

Dalam penelitian ini penggunaan hidden layer diterapkan 1, 5 dan 10 hidden layer. Tabel dibawah ini perbandingan hasil pelatihan berdasarkan jumlah hidden layer.

c. Nilai pembelajaran Learning Rate

Parameter laju pembelajaran memperkirakan besarnya penyesuaian bobot ketika dilakukan proses pembelajaran. Laju pembelajaran yang digunakan dalam penelitian ini merupakan default dari toolbox Matlab sebesar 0.01.

d. Momentum

Nilai momentum yang digunakan untuk menormalisasi learning rate agar tidak menyebar keluar dari batasan. Nilai momentum yang digunakan adalah default dari toolbox Matlab sebesar 0.075. Berdasarkan dari proses pelatihan yang telah dilakukan bahwa dapat dilihat bahwa hasil eror terkecil didapatkan pada hidden layer 5, dimana eror 0.019553 dengan $\mathrm{R}^{2}$ sebesar 0.84 .

Dari hasil pelatihan Jaringan syarat Tiruan mendapatkan hasil pengaruh dari 5 faktor terhadap Implementasi Sistem Informasi sebesar $84 \%, 12 \%$ dipengaruhi oleh faktor lain.

TABEL IV

HASIL UJI BERDASARKAN HIDDEN LAYER

\begin{tabular}{ccc}
\hline $\begin{array}{c}\text { Hidden } \\
\text { layer }\end{array}$ & MSE & Koefisien $\left(\mathrm{R}^{2}\right)$ \\
\hline 1 & 0.023967 & 0.90227 \\
5 & 0.019553 & 0.84165 \\
10 & 0.1378 & 0.9014 \\
\hline
\end{tabular}

\section{Kesimpulan}

Dari hasil analisis faktor yang dilakukan dalam penelitian ini ditemukan 5 (lima) faktor baru yang mempengaruhi implementasi Sistem Informasi pada sekolah-sekolah menengah kejuruan Negeri di Jakarta Timur yaitu Availability Manage IT, Availability Manage security, improvement quality System, quality information System, manage performance readiness.

Hasil pengolahan data dengan jaringan syarat tiruan menghasilkan koefesien determinasi sebesar $84 \%$ sedangkan pengolahan data dengan analisis regresi mendapatkan koefesien determinasi sebesar $80.7 \%$. Sehingga penelitian ini berdasarkan hasil pengolahan data diambil dari metode JST dari faktor-faktor yang didapatkan dari kematangan TI, kinerja dan pemanfaatan
Teknologi informasi mempunyai pengaruh yang kuat terhadap Implementasi Sistem Informasi sebesar $84 \%$.

\section{Saran}

Hasil penelitian ini jauh dari sempurna, maka sebaiknya dilakukan penelitian selanjutnya dengan:

a. Jumlah populasi Sekolah harus semua sekolah baik Negeri maupun swasta yang ada di wilayah Jakarta Timur

b. Untuk selanjutnya gunakan keseluruhan dari setiap Domain COBIT.

c. Metode pengumpulan data jangan hanya terpaku pada jawaban hasil kuesioner tetapi dilakukan dengan tools lainnya

\section{Ucapan Terima Kasih}

Peneliti mengucapkan terima kasih kepada pihak SMK Negeri 5, SMK Negeri 26 dan SMK Negeri 48 yang telah membantu dan memfasilitasi penelitian ini sehingga dapat berjalan lancar. Terima kasih kepada bapak Wahyu Sardjono, S.Si, MM., Dr. yang telah membimbing dalam melakukan penelitian ini sehingga penelitian selesai tepat waktu.

\section{Referensi}

[1] Eko Indrajit, Richardus. (2006). Mengukur Tingkat Kematangan Pemanfaatan Teknologi Informasi untuk Institusi Pendidikan Suatu Pendekatan kesiapan pemegang kepentingan (Stakeholder).

[2] Chandarin Grahita dan Nur Indriantoro, 1997, Hubungan antara Parisipasi dengan Kepuasan Pemakai dalam Pengembangan Sistem Berbasis Komputer: Suatu Tinjauan Dua Faktor Kontijensi, Tesis - UGM

[3] Karimi. El. (1996). Impact Of Competitive Strategy And Information Technology Maturity On Firm' Strategic Response to Globalization. 1996. Jurnal of Management Information systems/ Spring 1996, Vol. 12, No.4 PP.55-88.

[4] McLeod, R., 2000, Management Informaion System : A Study of Computer Based Information Systems, McMillan Publishing Co., New York

[5] Thomson, R.L, 1995, Task Technology Fit and Individual Performance, Management Information System, Quarterly, June :213236

[6] COBIT Steering Committee and The Governance Institute, COBIT 4.1 USA: IT Governance Institute. 2004 
[7] IT Governance Using COBIT® and Val IT $^{\text {TM: }}$ Caselets, 2nd Edition,(2007), ISBN 978-1-60420-027-0.

[8] Sembiring. (1995). Analisis Regresi, Bandung : ITB.

[9] A.Abu-Musa.(2009).Ahmad.Exploring. COBIT Processes for ITG in SaudiOrganizations: An empirical StudyThe International Journal of Digital Accounting Research Vol.9, 2009, pp.99-126ISSN: 1577-8517

[10] Gomes, Rui., Ribeiro, Jorge. (2009) Main Benefits Of Cobit In A High Public Educational Institution - A Case Study. Pacific Asia Conference on Information Systems(PACIS)PACIS 2009.

[11] Johnson, R. A. and Wichern, D.W. (1988), Applied Multivariate Statistical Analysis, Prentice Hall Inc,New Jersey.

[12] Kusumadewi, Sri. (2003). Membangun Jaringan Syaraf Tiruan menggunakan MATLAB \& EXCEL LINK.Graha Ilmu. ISBN:979-3289-1-0.

[13] Maria.el. (2011). The Measurement of Information Technology Performance In Indonesian Higher Education Institutions In The Context Of Achieving Institution Business Goals Using Cobit Framework Version 4.1. Juli 2012. International Refereed Research Journal www.researchersworld.com Vol-III,Issue3 (3), July 2012.

[14] Naja Anwar, Sariyun. (2009). Pengaruh Kematangan Teknologi Informasi dan Kinerja Sistem Informasi terhadap Kemanfaatan Sistem Informasi bagi Kelurahan-kelurahan di Kodia Semarang. Jurnal Teknologi Informasi DINAMIK Volume XIV, No.2, Juli 2009 : 146-151
[15] Prasetyo, Edy. (2011). Analisis dan Monitoring Implementasi Teknologi Informasi Perguruan Tinggi Menggunakan Control Objective For Information And Related Technology. Konfrensi Nasional System dan Informatika 2011; Bali, November 12, 2011.

[16] Setiawan, Alexander. (2010). Pengaruh kematangan, kinerja dan Pengembangan Teknologi Informasi di Perguruan Tinggi Swasta Yogyakarta dengan Model COBIT Framework. Seminar Nasional Informatika 2010 (Seminar IF 2010) UPN Veteran Yogyakarta, 22 Mei 2010.

[17] Sharma, Subhash (1996),Applied Multivariate Techniques, John Wiley \& Sons, Inc, New York.

[18] Spremic, Mario. (2012). Measuring IT Governance Performance: a Research Study on CobiT- Based Regulation Framework Usage. International Journal of Mathematics And Computers In Simulation ISsue 1, Volume 6, 2012.

[19] Tanuwijaya, Haryanto., Sarno, Riyanarto. (2010) Comparation of CobiT Maturity Model and Structural Equation Model for Measuring the Alignment between University Academic Regulations and Information Technology Goals. IJCSNS International Journal of Computer Science and Network Security, VOL.10 No.6, June 2010

[20] Tarmidi, Mahlindayu.el. (2011). Exploring The Approaches For Cobit Process In Malaysian 100 Top Corporate Governance Companies. 3rd International Conference On Business And Economic Research (3rd ICBER 2012) Proceeding 12- $13 \mathrm{MARCH}$ 2012. Golden Flower Hotel, Bandung, Indonesia ISBN: 978-967-5705-05-2. 